\title{
Risk Analysis for Overexposure Measurements Due to Radiological Accidents Using Computer Code and the Lessons Learned "Meet Halfa as a Case Study, Egypt"
}

\author{
Elsayeda Farid Salem \\ Egyptian Nuclear and Radiological Regulatory Authority, Cairo, Egypt
}

\section{Email address:}

sayeda_f@yahoo.com

To cite this article:

Elsayeda Farid Salem. Risk Analysis for Overexposure Measurements Due to Radiological Accidents Using Computer Code and the Lessons Learned "Meet Halfa as a Case Study, Egypt". American Journal of Physics and Applications. Vol. 5, No. 2, 2017, pp. 13-19. doi: 10.11648/j.ajpa.20170502.11

Received: January 24, 2017; Accepted: February 15, 2017; Published: March 3, 2017

\begin{abstract}
Large number of accidents that have occurred in three major practices, namely: industrial radiography, gamma irradiators, and radiotherapy. A radiological accident involves a sealed or unsealed radiation source leads to an uncontrolled release of ionizing radiation or radioactive materials into the environment, which may result in significant human exposure and/or material damage. A major accident occurred in greater Cairo Area during 2000 due to bad practice and human error. A radiological source (Ir-192 capsule with activity 31.5 Ci) was lost at the examination site near the pipe. Members of the public were plucked up. At least seven persons have exposed to overdoses, two of them died due to overexposure dose. In this study, the absorbed radiation doses and the associated hazards due to uncontrolled radioactive sources Ir-192 and Cs-137 are calculating using RESRAD-Building computer code. An overview of the consequences and the obtained results are registered in lessons learned study would clarify the necessary that the regulatory authority to introduce measures capable to avoid the recurrence of similar accidents.
\end{abstract}

Keywords: Overexposure, Radiation Accident, Orphan Sources, Computer Code, Radiation Contamination

\section{Introduction}

Sealed radioactive sources are used widely in medicine, industry, and agriculture. A sealed radioactive source is radioactive material that is permanently sealed in a capsule or bonded and in a solid form. The capsule of a sealed radioactive source is designed to prevent the radioactive material from escaping or being released from encapsulation under normal usage and probable accident conditions. Radiation accidents primarily occur with radiation devices, such as sealed sources $\left({ }^{192} \mathrm{Ir},{ }^{60} \mathrm{Co}\right.$, and $\left.{ }^{137} \mathrm{Cs}\right)$ or X-ray devices for material testing (mainly radiography), which used in irradiation facilities or radiotherapy devices (used in medicine or research). A statistical data presented that about one half of radiation accidents are caused by 192Ir, and one quarter of them by $60 \mathrm{Co}$, while the remaining $23 \%$ is due to ${ }^{137} \mathrm{Cs}$, radium, uranium, transuranic elements or unknown isotopes (Fig 1) [1].

Accidental exposure of members of the public may occur due to loss of control over radiation sources used in radiotherapy, sterilizations, etc., and due to orphan sources [2]. Uncontrolled sources are called "orphan sources". Which is include abandoned, lost, misplaced, stolen or removed without authorization sources. There have been a large number of radiological accidents involving orphan sources. In some of these accidents, workers as well as members of the public were exposed to high levels of radiation resulting in hazard consequences [3]. Radiation overexposure accidents are uncommon, but can have severe long-term health consequences. Industrial and orphan sources accidents accounted together for most reported accidents between 1980 and $1989(60 \%)$, their proportion sharply decreased afterwards, reaching $17 \%$ of reported accidents between 2000 and 2009 [4].

The main causes of radiation accidents in various application areas are as follows:

-Weakness and ineffectiveness of both the legal or regulatory framework for radiation source 
-Lack of information on usual physical appearance and possible harm of radiation sources which may lead to accidental overexposure in case of unauthorized possession;
-Insufficiency of radiation protection and radiation safety regulations, or their deficient application.
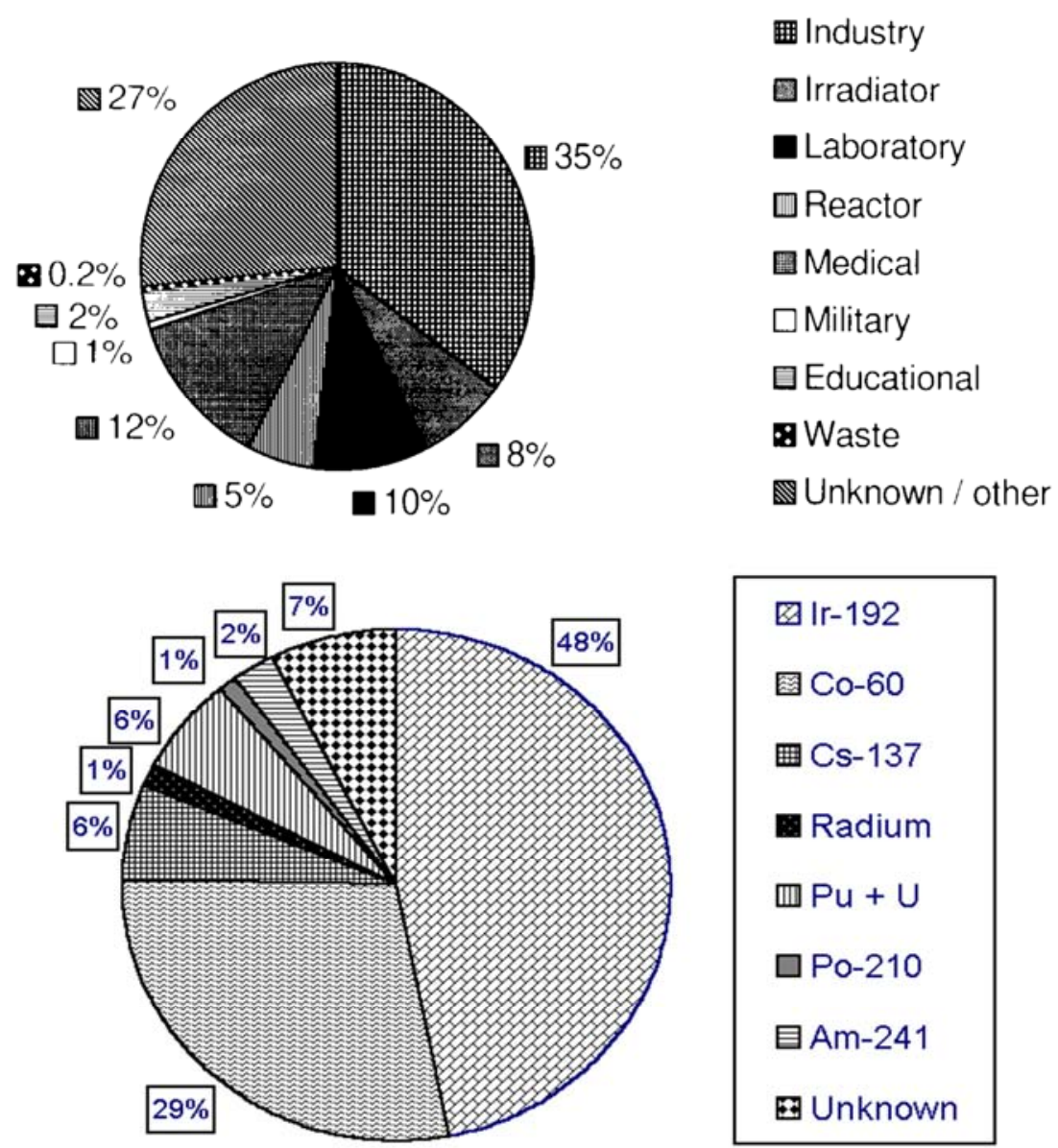

Figure 1. Distribution of radiation accidents, according to the type of facility and the radioisotopes involved, 1945-2000.

A review of published information shows that the main victims of accidents involving industrial radiography sources were members of the public and workers who were not associated with the use of the source. A common feature of this type of accident is that the source becomes separated from its shielded container. To the untrained eye, this unshielded source appears to present little hazard and often persons have put the source in their pocket and taken it home, resulting in death or the amputation of limbs [5]. Numerous accidents, where sealed radioactive sources have been lost or abandoned, illustrate the potential danger from sealed radioactive sources when proper precautions for safe and secure storage are not followed [1]. In most countries, the use of sealed radioactive sources is regulated and users are required to be properly educated and trained in radiation safety and protection. Dose limits for individuals have been adopted by the International Community in the Radiation Protection and Safety of Radiation Sources: International Basic Safety Standards for protecting people and the environment. In March 1984, a serious radiation incident occurred in Morocco in which eight members of the public died of overexposure from a radiographies source. A 1100 $\mathrm{GBq}(30 \mathrm{Ci}){ }^{192} \mathrm{Ir}$ source became disconnected from the drive cable and was not properly returned to its shielded container. Subsequently, the guide tube was disconnected from the exposure device and the source eventually dropped to the ground, where a passerby picked up the tiny metal cylinder and took it home. Although the exposure device was marked with the international radiation caution symbol, the source itself bore no markings. The source was lost from March to June and a total of eight persons, including the passer-by, members of his family and some relatives, died; the clinical diagnosis was 'lung haemorrhage'. It was initially assumed that the deaths were from poisoning. Only after the last family member had died it was suspected that the deaths might have been caused by radiation [6]. A radiographer failed to retract the $3000 \mathrm{GBq}(81 \mathrm{Ci}){ }^{60} \mathrm{Co}$ source being used. He entered the enclosure without using a survey meter and while the radiation alarms were defeated. The radiographer was not wearing a personal dosimeter. A production co-ordinator working with the radiographer also entered the enclosure; he, too, was not wearing a personal dosimeter. The radiographer changed the films, adjusted the source collimator and exited the enclosure, together with the production co-ordinator. When the radiographer attempted to crank the source out to the exposed position, he realized that 
the source had not been retracted on the previous exposure and that he and the production co-ordinator had been exposed. The incident demonstrated that the radiographer probably received a dose to his eyes of $90 \mathrm{mSv}$ and a dose to those portions of the hand with which he had adjusted the source collimator that was in excess of $42.5 \mathrm{~Sv}$. The production co-ordinator received a dose to his eyes of 40 mSv [7]. In 1987 in Goiânia, a private medical partnership specializing in radiotherapy broke up acrimoniously. No one took responsibility for a $50 \mathrm{TBq}{ }^{137} \mathrm{Cs}$ teletherapy unit that was left abandoned in the partially demolished building of the former clinic. After two years, some local people dismantled the source and its housing and removed it for its scrap metal value. In the process the source was ruptured. The radioactive material was in the form of compacted cesium chloride, which is highly soluble and readily dispersible. For over two weeks the radioactivity was spread over parts of the city by contact contamination and resuspension. Contaminated items (and people) went to other parts of the country. The recognition of the existence of the problem was triggered by an increasing number of health effects. Overall some 249 people were externally contaminated, 129 internally, 21 people received in excess of 1 Gy and were hospitalized, of which 10 people needed specialized medical treatment but 4 of those dying. The decontamination and clean-up of the environment took 6 months of intensive effort and produced 3, 500 tonnes of active waste [8]. In 2000 due to bad practice and human error Ir-192 capsule was lost near the pipe at the examination site. It was found one month later inside the house of a farmer living in meet half village (a few kilometers from Cairo railway station). The competent authorities were not informed of the lost capsule and the company did not report it missing. Two persons died before the capsule was found. This led to major public health concern, which led to locate the capsule [9].

\section{Material and Method}

a) Description of the scenarios:

The RESRAD-BUILD computer code is a pathway analysis model developed to evaluate the potential radiological dose incurred by an individual who works or lives in a building contaminated with radioactive material. The exposure pathways considered include external and internal exposure. Figure 2 illustrates the main window that appears when RESRAD-BUILD is started.

All the pathways considered in the RESRAD-BUILD code:

1. External exposure to penetrating radiation emitted directly from the source,

2. External exposure to penetrating radiation emitted from radioactive particulates deposited on the floors of the compartments,

3. External exposure to penetrating radiation due to submersion in airborne radioactive particulates,

4. Inhalation of airborne radioactive particulates,

5. Inhalation of aerosol indoor radon decay products and triturated water vapor,

6. Inadvertent ingestion of radioactive material contained in removable material directly from the source

7. Inadvertent ingestion of airborne radioactive particulates deposited on the surfaces of the building.

The first three pathways would result in external exposure, and the last four would result in internal exposure due to internal contamination of the exposed individual. In RESRADBUILD, the external radiation doses are evaluated as the effective dose equivalent, and the internal exposure is evaluated as the committed effective dose equivalent (CEDE) [10].

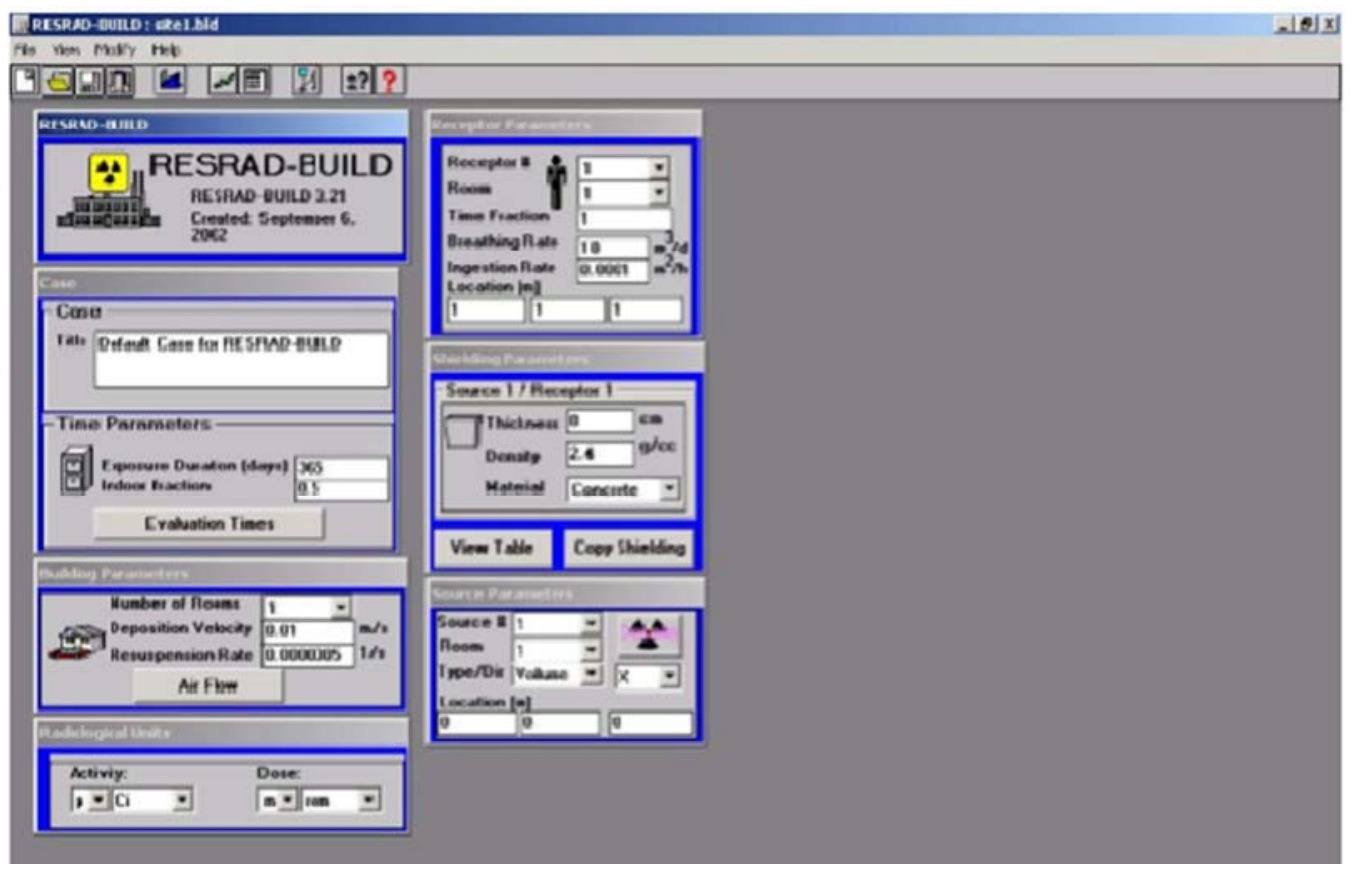

Figure 2. Main Menu for RESRAD-BUILD code. 


\section{b) Model input parameters:}

\section{b.1. Frist scenario:}

The accident occurred following the loss of a radiography industrial source ${ }^{192} \mathrm{Ir}$. A farmer from Meet Halfa found the source and took it to the house occupied by his family. The sequence of events followed were developed over a period of seven weeks from the time the source was found on May $5^{\text {th }}$ in 2000, until the day of its retrieval from the house by national authorities on June $26^{\text {th }}$ in 2000 [9]. The source length is $18 \mathrm{~cm}$ with an 8 - by $4-\mathrm{mm}$ active volume at one end. The half-life of ${ }^{192} \mathrm{Ir}$ is 74 days. The source activity would have been $31.5 \mathrm{Ci}(1.17 \mathrm{TBq})$ on May 5 , the day the source was found and came into possession of the family. On June 26, the day the source was retrieved, its activity would have been $19.34 \mathrm{Ci}(0.7156 \mathrm{TBq})$. The family members were in possession of the source from May $5^{\text {th }}$; they included the father (60 years old), the wife (50 years), the sister of the father (55 years), the sons $(9,22$ years), the daughters $(13,17$ years). Table 1 represents the the distance away the source and the exposure time for every receptor.

Table 1. The distance away the source and the exposure time for the receptors.

\begin{tabular}{|c|c|c|}
\hline Receptor & $\begin{array}{l}\text { Distance away the } \\
\text { source (m) }\end{array}$ & Exposure time (h) \\
\hline Farmer & 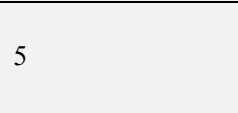 & $\begin{array}{l}14 \text { hours every day in the first } \\
20 \text { days and } 24 \text { hours in the last } \\
22 \text { days }\end{array}$ \\
\hline Old son & 5 & 14 hours every day for 52 \\
\hline Young son & 5 & 14 hours every day for 31 days \\
\hline Wife & 6 & 24 hours every day for 52 days \\
\hline Sister & 6 & 24 hours every day for 52 days \\
\hline Old daughter & 6 & 24 hours every day for 52 days \\
\hline Young daughter & 6 & 14 hours every day for 52 days \\
\hline
\end{tabular}

\section{b.2. Second scenario:}

The Goiania accident was a radioactive contamination accident that occurred on September 13, 1987, in Goiânia, in the Brazilian state of Goiás, after an old radiotherapy source was stolen from an abandoned hospital site in the city. The radiation source in the Goiânia accident was a small capsule containing about 93 grams of highly radioactive cesium chloride (a calcium salt made with a radioisotope, cesium137) encased in a shielding canister made of lead and steel. The source was positioned in a container of the wheel type, where the wheel turns inside the casing to move the source between the storage and irradiation positions [11]. The source contained $50.9 \mathrm{Ci}(1.38 \mathrm{TBq})$ when it was taken. The exposure time 13 to 28 September was 16 days. Devair Alves Ferreira who brought it into his house on September 18. Over the next three days, he invited friends and family to view the strange glowing substance. On September 25, 1987, Devair Alves Ferreira sold the scrap metal to a second scrapyard. The absorbed doses by the owner, his wife 37 -year-old and his friends were calculated according to the exposure time represented in table (2).
Table 2. The exposure time for the receptors

\begin{tabular}{ll}
\hline Receptor & Exposure time (h) \\
\hline Devair Alves Ferreira & 98 \\
wife & 168 \\
Friends & 15 \\
\hline
\end{tabular}

c) Theoretical calculation for absorbed dose:

The estimated values of the absorbed doses by the RESRAD building code in this study can be validated with the calculated theoretical values depending on the following equation [12]

$$
\mathrm{D}=\frac{\Gamma \mathrm{A}}{d^{2}} \mathrm{~T}
$$

Where D: absorbed dose in mGy

A: is source activity $(\mathrm{MBq})$

$\Gamma$ : is a gamma conversion factor for the source, $\mathrm{mSv} / \mathrm{h}$ $(\mathrm{GBq})$ at $1 \mathrm{~m}=(0.13)$

$\mathrm{d}$ : is the distance from the point source $(\mathrm{m})$

$\mathrm{T}$ : exposure time $(\mathrm{h})$

RESRAD - Building Code results validated with equation (1) calculations using the same condition.

\section{Results and Discussion}

The obtained results by the used code (RESRAD Building code) are represented and analyzed in this section for the above mentioned scenarios. In the Meet Halfa scenario figure 3 represents the pathway of external doses for the farmer family members according to their exposure duration time and the distance away the source which illustrated in table (1). It is clear that although the highest dose for farmer (father ) and older son, the younger son died in 5 June (after 31 days) and the father in 16 June (after 42 days). This results indicate that the age factor since the highly affected members of the family were the son 9 years old and his fathe 60 years old respectively. Figure 4 illustrates the received absorbed dose during the exposure time for the farmer family member. It is obvious that the absorbed dose for the father was the highest dose, 5.39 Gy, then the older son 5.05 Gy while the absorbed dose by the younger son has $3.7 \mathrm{~Gy}$. These results are within the range of agreement if they compared with the results obtained by equation (1). The younger son and his father have the lowest exposure time as shown in table (1). Both died because of bone marrow failure, sever skin burns and gastrointestinal manifestations [13]. The effect of the accident was overdose exposure, where there is no contamination because the source was not damage. The Meet Halfa radiation accident was classified by using the International Nuclear Events Scale (INES) as Level 4, which is the first level of accident classification. In general, this scale applies to emergencies involving: sources, transport, severe over-exposure, and terrorist threats or criminal activities. ${ }^{192}$ Ir source found in Meet Halfa which caused the accident is classified according to the categorization of sources by the IAEA in category $2(\mathrm{~A}=1.165 \mathrm{TBq}, \mathrm{D}=$ 
0/1/38 TBq, and $\mathrm{A} / \mathrm{D}=14 / 1 / 3)[14]$.

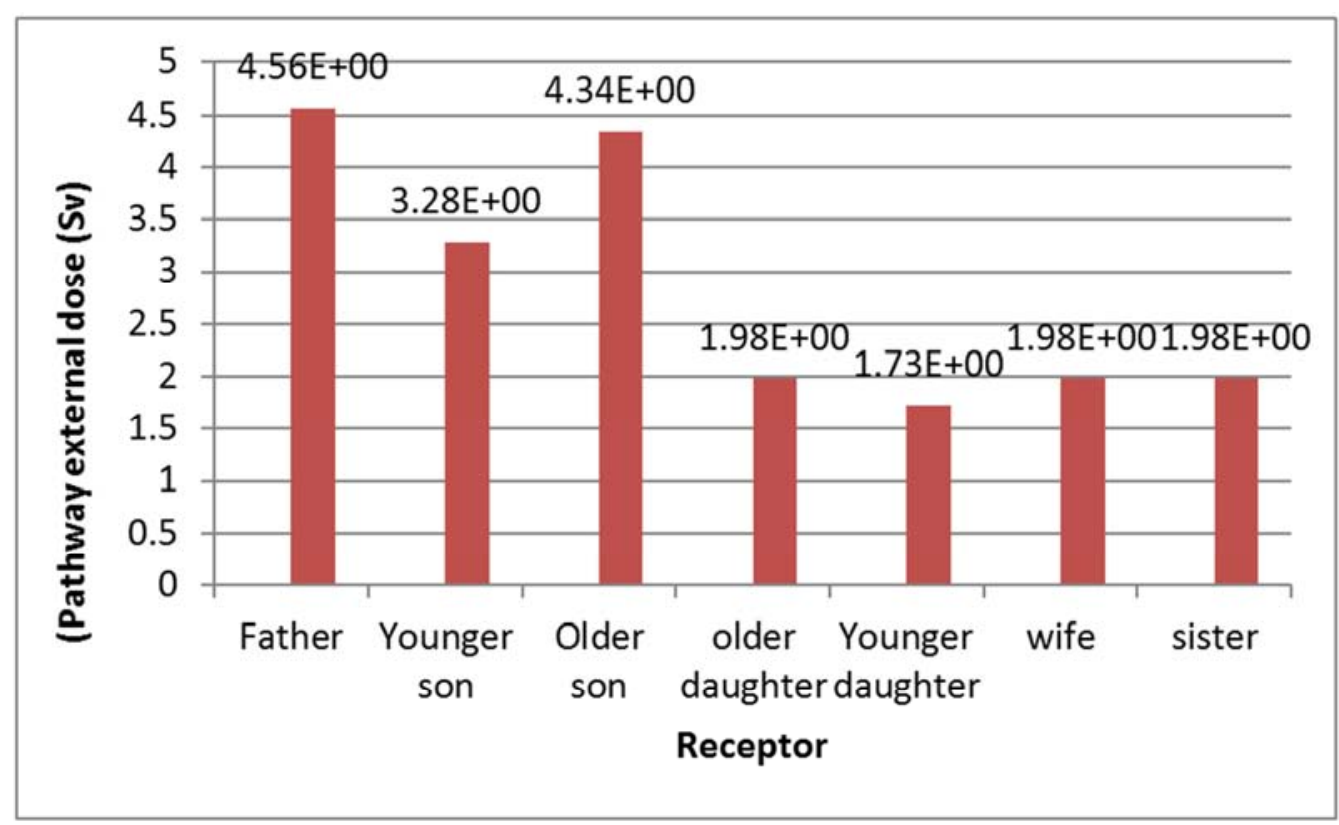

Figure 3. Pathway Doses from Ir-192.

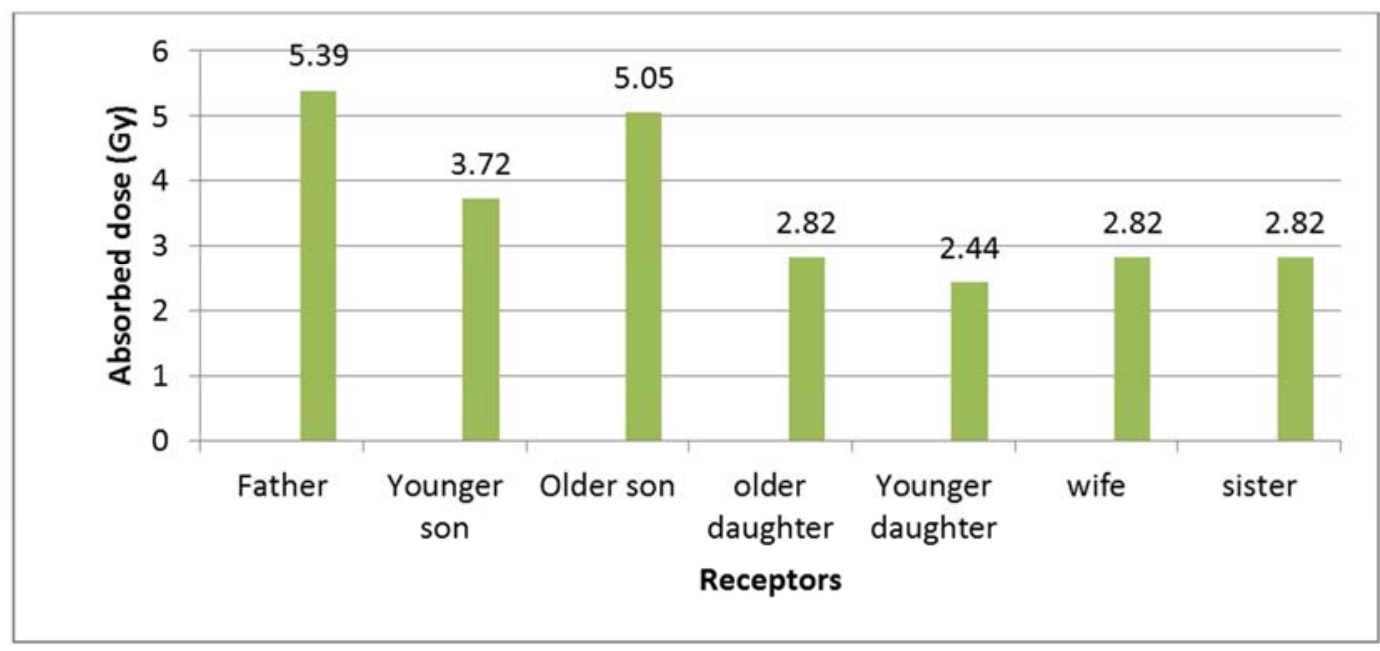

Figure 4. Receptor received Dose due to Meet halfa accident.

For Goiania accident scenario the pathway doses and absorbed dose from Cs-137 source with activity (50.9 TBq) are represented in figures 5, 6 respectively. These obtained results by the used code were estimated according to exposure duration time illustrated in table (2) for the scrapyard owner, his wife and his friends respectively. It is clear that owner wife (37years old) is the most affected person science the most external dose about $(5.9 \mathrm{~Sv})$ was deliver to her. This is in agreement with the results of earlier studies (5.7 Sv) [15]. Illness symptoms were appeared on the wife during about three days after coming into contact with the substance. Her condition worsened, internal bleeding, especially in the limbs, eyes, and digestive tract, and hair loss. She suffered mental confusion, diarrhea, and acute renal insufficiency before dying on October 23, 1987, of "septicemia and generalized infection", about a month after exposure.
Several people survived high doses of radiation which may be due to the fractionated doses. Because of the given time, the body's repairs mechanisms repair mechanisms will reverse cell damage caused by radiation. If the dose is spread over a long time period, these mechanisms can mitigate the effects of radiation poisoning. Afterwards, about 112, 000 people were examined for radioactive contamination; 249 were found to have significant levels of radioactive material in or on their body. Of this group, 129 people had internal contamination. The majority of the internally contaminated people only suffered small doses $(<50 \mathrm{mSv}$, less than 1 in 400 risk of getting cancer as a result). Goiania radiation accident was classified by using the International Nuclear Events Scale (INES) as Level 5, accident with wider consequences. About $44 \mathrm{TBq}(1200 \mathrm{Ci}, 87 \%)$ of contamination had been recovered during the clean-up operation, which means that $7 \mathrm{TBq}(190 \mathrm{Ci})$ remained in the 
environment; and have decayed to about $3.5 \mathrm{TBq}(95 \mathrm{Ci})$ by 2016. The accident was contamination accident so the hazard much larger relative to Meets Halfa accident. A Cs-137 source in Gauiana accident is classified also category 2 $(\mathrm{A}=50.9 \mathrm{TBq} \mathrm{A}=0 / 1 / 3$ and $\mathrm{A} / \mathrm{D}=500)$.

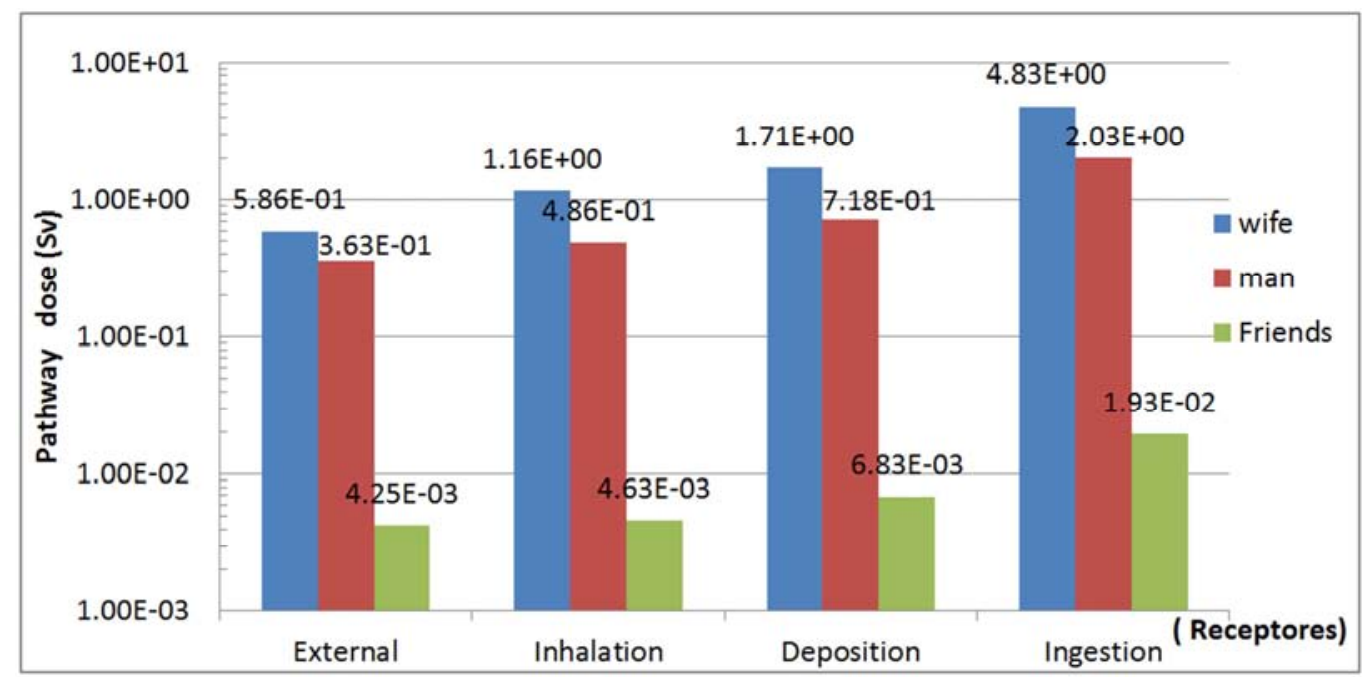

Figure 5. Pathway dose for Cs-137.

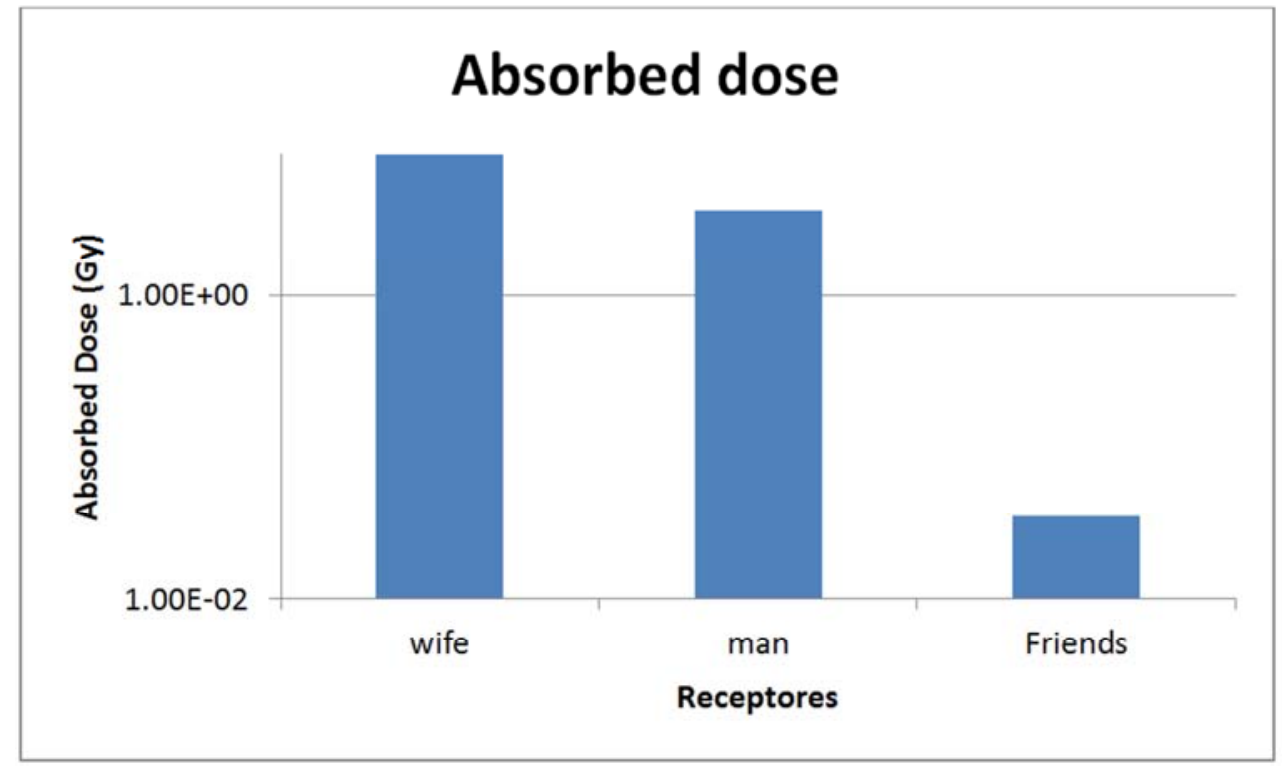

Figure 6. Absorbed dose Cs-137 sources.

\section{Lessons Learned:}

The accident at Meet Halfa provides several insights and defines generic lessons to be learned from the opinion of regulatory authorities, source operators, manufacturers, and individuals responsible for the safety of radiation sources. The operating organization is responsible for the possession and use of the industrial radiographic sources and devices. This includes their operation in accordance with regulatory authority regulations. The dissemination of operational experience can avoid accidents elsewhere.

Some of the important aspects that should be considered are: proper implementation of the codes of practice, minimizing the probability of human error by repeated educational training programs, minimizing the probability of source malfunction by repeated maintenance; stringent supervision over the logistics involved in the importing, licensing, transporting, and recording of sources; and formulation of a proper system for dealing with spent sources. The radiographers must have good training and radiation surveys to insure that the source had been returned to the fully shielded position. One lesson learned from the accident at Meet Halfa is the great importance of the credibility of the information given to the public and of the continual updating of that information. Communication with the public, both before and during an emergency is important as a means to limit potential damages from a missing source and to provide guidance on what can or should be done. Some of the incidents described occurred due to lack of information or knowledge [16]. Before Egyptian nuclear law no. 7 for the year 2010 all sealed sources used in industries 
and medical propose under the approval of the Ministry of health. Egyptian nuclear law no. 7 regulates the nuclear and radiation activities. Under the title of import, export, transport, and transit, Article (55) prohibited, without the approval of the ENRRA (Egyptian Nuclear and Radiological Regulatory Authority ), import, export, or transfer of any radioactive material or any component or product of radiological nature, except $\mathrm{X}$-ray machines, for use in the medical field that are under the approval of the Ministry of Health [17].

\section{Conclusion}

During normal usage, appropriate controls should ensure minimal risks. However if these sources are removed from their housings in an unauthorized manner they can deliver a lethal dose in a short period of time. Once the containment of a caesium chloride source is breached, the high mobility of the material causes a rapid spread of contamination. Thus the problem is higher from sources with chemical forms that can easily be dispersed. Radiotherapy and industrial radiography are practices that are subject to licensing. Licensing requirements include mandatory safety assessment. Regulatory authorities should prioritize their resources and devote a high level of control to those practices with a high potential for accidents. Training programs is needed for radiation protection officers and those workers in high risk practices, such as industrial radiography and radiotherapy facilities. An obligation to notify of any temporary or permanent disuse of sources or their removal from operational use, would allow the regulatory authority to perform a closer follow up of all sources no longer in use and prevent loss of control of these sources. National regulatory requirements should include an obligation to report missing and found sources and abnormal events with radiation sources. Disused sources represent the largest pool of vulnerable and potential orphan sources. The number of reported events in a single country is usually insufficient to provide a significant number of lessons in a reasonable time. However, a compilation of accidents at the international level would allow all countries to benefit from the lessons from each of them.

\section{References}

[1] International Atomic Energy Agency "Sealed Radioactive Sources" Austria, October 2013

[2] International Atomic Energy Agency "Radiation Accidents: Occurrence, Types, Consequences, Medical Management, and the Lessons to be Learned" CEJOEM 2001, Vol/1/3. No/1/3.:3-14.

[3] International Atomic Energy Agency "The Radiological Accident in Gilan" IAEA, Vienna (2002)

[4] Karen Coeytaux. et. al. "Reported Radiation Overexposure Accidents Worldwide, 1980-2013: A Systematic Review" National Centre For Biotechnology information (NCBI) Journal, 2015.

[5] P. Ortiz, M. Oresegun, J. Wheatley "Lessons from Major Radiation Accidents" International Atomic Energy Agency T21-1, P-11-230.

[6] UNITED STATES NUCLEAR REGULATORY COMMISSION, Lost Iridium-192 Source Resulting in the Death of Eight Persons in Morocco, Information Notice No. 85-57, NRC, Washington, DC (1985).

[7] International Atomic Energy Agency "LESSONS LEARNED FROM ACCIDENTS IN INDUSTRIAL RADIOGRAPHY" SAFETY REPORTS SERIES No. 7 VIENNA, 1998.

[8] International Atomic Energy Agency "STRENGTHENING CONTROL OVER RADIOACTIVE SOURCES IN AUTHORIZED USE AND REGAINING CONTROL OVER ORPHAN SOURCES", IAEA, VIENNA, 2004.

[9] El-Naggar, A. M., M. H. M. Mohammad and M. A. Gomaa, proceedings of the fourth international REAC/TS conference on The Medical Basis for Radiation - Accident Preparedness, Florida, March 2001.

[10] United States Department of Energy "User's Manual for RESRAD-BUILD Version 3", June 2003.

[11] International Atomic Energy Agency "The Radiological accident in Goiânia", Vienna:. 1988.

[12] IAEA "Generic procedures for assessment and response during a radiological emergency" TECDOC-1162, 2000, ISSN $1011-4289$

[13] El Naggar, A. M., Medical Radiation Biology, Al-Tobgy press, 2009

[14] IAEA, the International Nuclear and Radiological Event Scale, 2009).

[15] Malheiros, Tania "Histórias secretas do Brasil nuclear" (in Portuguese). Rio de Janeiro: WVA. p. 122. ISBN 9788585644086 (1996).

[16] S. R. Al Saadi and J. Ramsey "Management of Emergencies and Safety and Security Relevant Events Involving Radioactive Sources", IAEA, Proceedings of an International Conference Abu Dhabi, U. A. E. 27-31 October 2013.

[17] Egyptian Nuclear Law No. 7 for the Year 2010 to Regulate the Nuclear and Radioactive Activities. Official Gazette No. 12, Year No. 53, dated 30 March 2010. 